\title{
Social factors and height of primary schoolchildren in England and Scotland
}

\author{
R. J. RONA, A. V. SWAN, AND D. G. ALTMAN \\ From the Department of Community Medicine, St. Thomas's Hospital Medical School, London
}

SUMMARY In 1972 the height of 7601 children aged five to $11 \cdot 5$ years in England and of 2214 in Scotland was measured. Their parents were asked to complete a questionnaire to provide social and anthropometric information. A sequence of linear models was fitted to the data to assess the associations between social and biological factors and height. At the time of the study it was found that sibship size, father's social class, and his employment status all had a significant relationship with child's height; however, parents' height and child's birthweight both accounted for relatively more of the variance in child's height than father's social class and employment status. In England, sibship size significantly influenced the height of children of manual workers, but not that of nonmanual workers' children. In Scotland, sibship size was associated with height in all social groups. Surveillance and possibly intervention in a wide range of activities should be directed at socially more deprived groups; for example, in Social Class V, in which there are more large families and unemployment is more common.

Changes in the food policy of the British Government in 1971 led to the setting up of a Nutritional Surveillance Subcommittee of the Committee on Medical Aspects of Food Policy to advise on any unforeseen adverse health effects. The subcommittee emphasised that the height of children is the most sensitive measure of inadequate nutrition, and it recommended that anthropometric surveys should be carried out (Department of Health and Social Security, 1973). Our unit was asked to undertake the surveillance of the health and growth of primary schoolchildren in England and Scotland.

One of the aims of this study is to assess whether changes in social circumstances affect growth. Here we present the baseline data collected in 1972, and describe the influence on attained height of certain social factors such as father's social class and employment status; we also compare the influence of such factors with that of biological factors such as birthweight and parents' height.

\section{Methods}

The study design is mixed longitudinal. Twenty-two areas in England and six in Scotland were selected by stratified random sampling, with proportionately more areas selected from poorer social groups. Further details of the sampling procedure can be found elsewhere (Irwig, 1976). The study population comprised 9815 children between the ages of five and 11.5 years, of whom only $1 \%$ were of Asian or West Indian origin. Each child is measured once a year, and two weeks before a measurement session parents are asked to complete a questionnaire.

Local nurses, most of them health visitors or school nurses, were trained to measure height by the method described by Tanner et al. (1966); they were supervised by three St. Thomas's Hospital fieldworkers. Ten per cent of the sample was measured both by the local nurses and by our fieldworkers. The mean and standard deviation (SD) of the differences between the measure of children's height obtained by 50 nurses in the 28 areas and the three fieldworkers were on average $-0.02 \mathrm{~cm}$ (SD 0.4cm).

Data on father's social class and employment status (whether or not he was employed in the previous four weeks), parents' height, sibship size (all living siblings), child's birthweight and mother's age at the birth of the study child were obtained from the questionnaire. Children were classified into six social class groups according to the occupation of the father or male guardian (Registrar General, 1970).

The accuracy of reported birthweight was assessed by comparing the responses to questionnaires of 60 subjects whose children were at primary school with birthweight data provided by the area health 
authority. Reported birthweights were on average 63g (SD 165g) higher than recorded birthweights. The accuracy of reported parental height was assessed by measuring 50 parent couples (without warning) after they had completed the questionnaire. On average, reported height was greater than measured by $+1.4 \mathrm{~cm}(\mathrm{SD} 2.6 \mathrm{~cm})$ for mothers and $+2.0 \mathrm{~cm}(\operatorname{SD~} 4 \cdot 1 \mathrm{~cm})$ for fathers. Thus, the reported height of mothers was more accurate than that of fathers, possibly because the questionnaires were usually completed by the mother.

Height was measured in $99.7 \%$ of the 9815 children, and questionnaires were returned for $92 \%$, but some were incomplete. Table 1 shows how the responses varied with the different items used in the analysis.

Table 1 Response rate per item for England and Scotland (1972)

\begin{tabular}{|c|c|c|c|c|}
\hline & \multicolumn{2}{|l|}{ England } & \multicolumn{2}{|l|}{ Scotland } \\
\hline & $\begin{array}{l}\text { No. of } \\
\text { children }\end{array}$ & $\%$ & $\begin{array}{l}\text { No. of } \\
\text { children }\end{array}$ & $\%$ \\
\hline $\begin{array}{l}\text { Height } \\
\text { Birthweight } \\
\text { Sibship size } \\
\text { Fathers' social class* } \\
\text { Fathers' employment status } \\
\text { Fathers' height } \\
\text { Mothers' height } \\
\text { Mothers' age } \\
\text { Total no. of children }\end{array}$ & $\begin{array}{l}7576 \\
6835 \\
6736 \\
5414 \\
6450 \\
5995 \\
6288 \\
5775 \\
7601\end{array}$ & $\begin{array}{l}99 \cdot 7 \\
89 \cdot 9 \\
88 \cdot 6 \\
71 \cdot 2 \\
84 \cdot 9 \\
78 \cdot 9 \\
82 \cdot 7 \\
76 \cdot 0 \\
-\end{array}$ & $\begin{array}{l}2208 \\
1913 \\
1903 \\
1605 \\
1851 \\
1773 \\
1837 \\
1763 \\
2214\end{array}$ & $\begin{array}{l}99 \cdot 7 \\
86 \cdot 4 \\
86 \cdot 0 \\
72 \cdot 5 \\
83 \cdot 6 \\
80 \cdot 1 \\
83 \cdot 0 \\
79 \cdot 6 \\
\end{array}$ \\
\hline
\end{tabular}

*Children who could not be classified according to fathers' social class either because the information on fathers occupations was insufficient or because the fathers' occupations could not be classified, were excluded.

The results are presented separately for Scotland and England. Analysis was performed in two stages: (1) A preliminary analysis was made of height in relation to social class and each of the other environmental variables; (2) A sequence of linear models was fitted to the data in order to determine the extent to which each factor was associated with variation in height. Some of the factors included in the model were continuous variables and others were divided into categories. We will refer to this statistical procedure as linear model fitting.*

In the first stage of analysis we used all the information available (Table 1), but in the second stage only children with complete information were included: $4885(64 \cdot 3 \%)$ in England and 1427 $(64.5 \%)$ in Scotland. It was unfortunate that nearly $36 \%$ of the sample had to be disregarded because of incomplete data, but apart from minor differences

*This is the same as a factorial analysis of variance with a number of covariates. The linear model terminology is adopted because it is more general. The classical 'analysis of variance' and 'multilinear regression' techniques are simply two special examples of the general technique of fitting linear models. The general linear model is a multilinear regression equation with dummy (present or absent) variables to represent the categorical variables. in family size and the manual/non-manual occupation distribution, the complete data group were similar to the whole.

The distribution of height was normal in both sexes for all ages. Most of the following analyses of height are expressed in terms of a Standard Deviation Score (SDS). This is calculated for each child as the difference between his height and the mean height of a population of the same age and sex divided by the standard deviation for that population. This method of expression almost completely removes the effects of age and sex on height, while standardising for the increasing variance between height and age in the range of five to 11.5 years. The SDS was calculated from our own measurements of height in the English 1972 data (Rona and Altman, 1977). The SDS appropriate for the exact age of the child was calculated by a regression technique. One SDS is equivalent to about $5 \mathrm{~cm}$ at the age of five years and $7 \mathrm{~cm}$ at the age of 11 .

\section{Results}

\section{PRELIMINARY ANALYSIS}

Fig. 1 shows the 3rd, 50th, and 97th centiles of height of English boys in 1972 according to their fathers' occupations, classified as manual and non-manual.

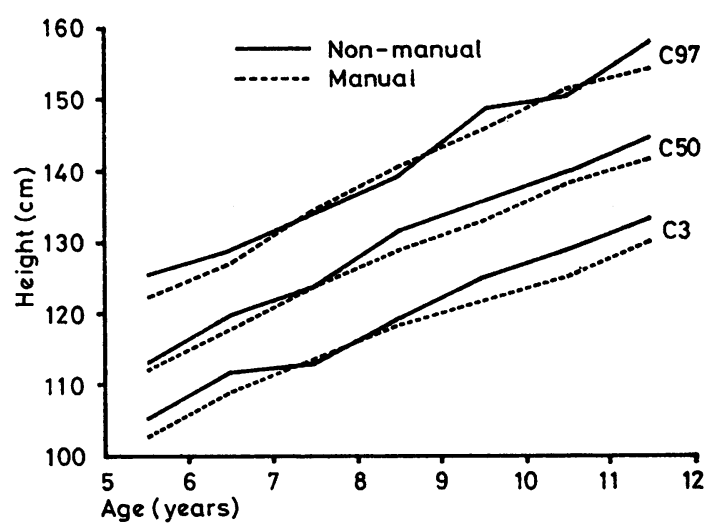

Fig. 1 Third, 50th, and 97th centiles of height of English boys in 1972 according to the occupational status of their fathers.

The children of fathers in a non-manual occupation were taller at most ages. At the 50th centile the difference was nearly $2 \mathrm{~cm}$ for most age groups, and at the 3 rd centile it was nearly $4 \mathrm{~cm}$. A similar pattern was found for girls. Those with fathers in a non-manual occupation were taller than girls from the manual classes in six of the seven age groups. The difference of the medians ranged between $1 \cdot 0$ and $2 \cdot 2 \mathrm{~cm}$. 


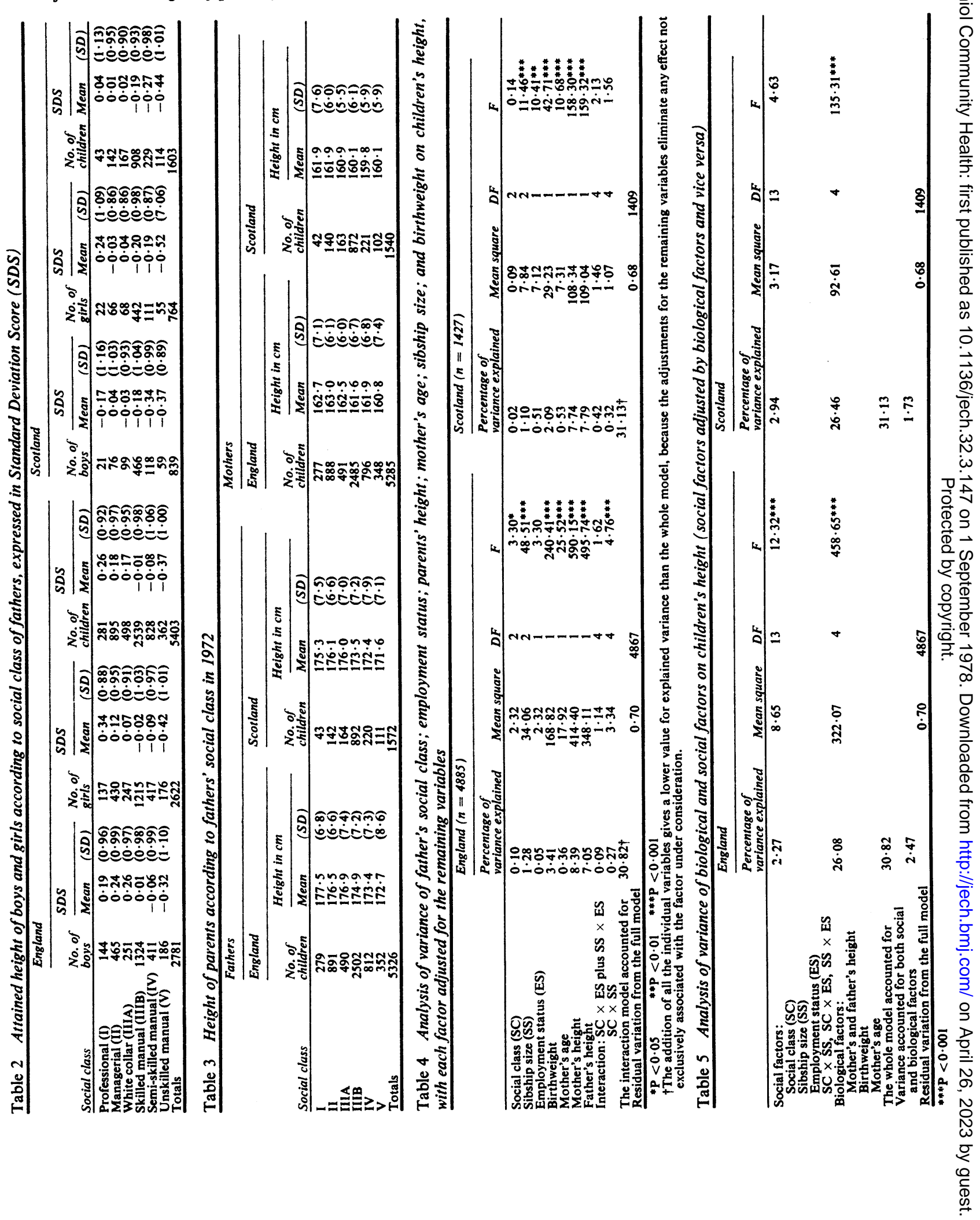


Table 2 shows attained height expressed in SDS for England and Scotland separately, subdividing the children according to sex and father's social class. In each social class group English children were taller than Scottish children, although the trends of attained height by social class were similar in the two countries. There was a small trend in the group of children with fathers in non-manual occupations, and children in the lower social strata were apt to be smaller than children from the non-manual classes; there was also a marked trend in the lower strata (Social Classes IIIB, IV, and V). Between Social Classes $I$ and $V$ the mean difference was approximately 0.6 SDS for England and 0.5 SDS for Scotland. The relationships between father's social class and height were consistently similar for both sexes in England and Scotland.

Figures 2 and 3 show attained height in SDS by sibship size for children in England and in Scotland with fathers in manual or non-manual occupations. In England, the influence of sibship size on height was most noticeable in the manual social class groups. In the non-manual groups, attained height decreased only for sibship size of five or more. In Fig. 2, the two lines are far from parallel, which

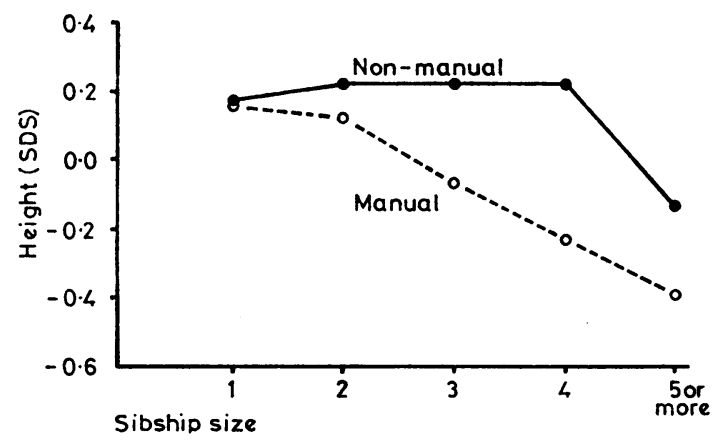

Fig. 2 Height of children in England expressed in Standard Deviation Score (SDS) according to the occupational status of their fathers and sibship size.

illustrates the different effects of sibship size in manual and non-manual groups. An analysis of variance showed that the interaction between social class and sibship size was significant $(P<0.001)$. In Scotland the 'interaction' was not significant, and the effect of sibship size on height was similar for both groups (Fig. 3). An analysis of variance showed that both the number of siblings and the father's social class were highly significant in their association with the attained height of Scottish children $(P<0.001)$. The same analyses carried out according to sex did not show a different

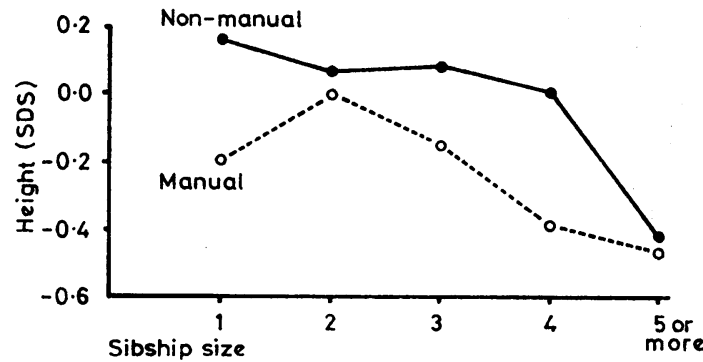

Fig. 3 Height of children in Scotland expressed in Standard Deviation Score (SDS) according to the occupational status of their fathers and sibship size.

pattern from the one described for the total group in either England or Scotland. The only point worth noting is that in England the interaction between social class divided into manual and non-manual occupations and the number of siblings was significant for girls $(P=0.01)$ and borderline for boys.

The unemployment figures in 1972 were $4.6 \%$ in the English sample and $11.5 \%$ in the Scottish sample. In England, $25 \%$ of the fathers in Social Class V $(6.7 \%$ of the total sample) were unemployed, compared with less than $5 \%$ in each of the other social classes. In Scotland, $32 \%$ of fathers in Social Class $V$ were at that time unemployed $(7 \cdot 4 \%$ of the total sample). In the other two manual social class groups in Scotland, there were $10 \%$ to $15 \%$ unemployed. In the non-manual social class groups, less than $5 \%$ were unemployed. Fig. 4 shows the effects of employment and social class of fathers on

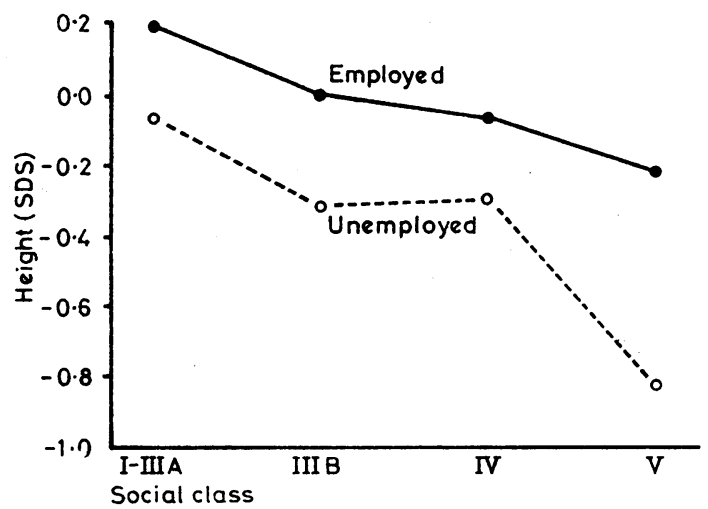

Fig. 4 Height of children in England expressed in Standard Deviation Score (SDS) according to social class and employment (or unemployment) of their fathers. 
attained height of English children expressed in SDS. All non-manual social class groups were combined because unemployment in these groups was low $(1 \cdot 1 \%)$. In each social class group, children with unemployed fathers were shorter. The difference in height between children of the employed and those of the unemployed was largest $(0.6$ SDS) in Social Class V, where unemployment was most common. The same pattern was observed in Scotland.

Table 3 shows the relationship between father's social class and parents' reported height in $\mathrm{cm}$ in England and Scotland. Fathers in the lower social class groups were, on average, shorter in both countries; this trend was less marked in mothers. In England, parents in each manual social class group were, on average, $3 \mathrm{~cm}$ shorter when the father was unemployed. In Scotland this relationship was less obvious.*

\section{LINEAR MODEL ANALYSIS}

All these social influences on children's attained heights diminished when adjustment was made for parental height. This led us to make a more general analysis. In this, we used linear models to assess the separate and combined effects on attained height (in SDS units) of father's social class; sibship size; employment status; birthweight; mother's age; and father's and mother's reported height. Father's social class was divided into three categories: (a) I, II, and III A (b) III B and IV and (c) V. Sibship size was also divided into three categories: (a) two or fewer (b) three and (c) four or more. The analysis was made separately for England and Scotland. The results were similar in both countries, and the variation in the children's heights in SDS attributable to these factors was $30.8 \%$ and $31.1 \%$ of the total variation in England and Scotland respectively.

Ideally, this sort of analysis should be performed using the package computer programme GLIM (Nelder, 1975). Unfortunately this had insufficient space for the complete data set. Because of this restriction, a preliminary analysis was performed using data from English boys only to discover whether, for example, children's birthweights and parents' heights were associated with attained height in ways that differed with employment status or any other factor. The analysis showed that this was not so and therefore such complications could safely be ignored. Consequently, it has been assumed that the associations of height with birthweight and parents' heights were similar for all social classes, for all types of employment status, and for all sibling size groups.

'Detailed tables can be provided on the relationship between parents' heights, social class groups, and employment status.
The factors included in the analysis are listed in Table 4. This shows the degree of association with attained height of each factor after adjustment for the remainder. Height of both mother and father had the strongest association with attained height in both England and Scotland. Birthweight and sibship size were also strongly associated with attained height but in Scotland birthweight was less important. Sibship size was equally important in both countries. Mother's age at time of birth was also associated with attained height but explained less of the variance than did the previously mentioned factors. These five factors were all highly significant $(P<0.001)$ in their association with attained height.

Only in England was social class significantly associated with attained height, and unemployment was significant only in Scotland. 'Interaction' between sibship size and social class was highly significant in England, although not in Scotland, which indicates that the contribution of sibship size to attained height should be interpreted separately for each social class group, at least in England.

In Table 5, we have arbitrarily distinguished between sibship size, employment status, and social class (classified as 'social' factors) and parents' heights, birthweight, and mother's age (classified as 'biological' factors). The 'biological' factors had a greater association with children's heights; and even when adjustments were made for social factors, the biological factors still explained $26 \%$ of the variation in children's heights. Social factors, after adjustment for the biological factors, explained $2.3 \%$ and $2.9 \%$ of the variation in England and Scotland respectively. The complete model explained nearly $31 \%$ of the variation in Scotland and England. The remaining $2.5 \%$ to $1.7 \%$ in England and Scotland is some sort of overlap in the effects of biological and social factors.

\section{Discussion}

We have shown in this analysis that the height of children is associated with social and biological factors, and that the latter are responsible for the bulk of the 'explained' variation. As in previous studies, parental height was the most important factor. From data collected in the 1958 cohort study, Goldstein (1971) fitted a multifactorial model for seven-year-old children; mother's height (fathers were not measured), birthweight, and mother's parity had the strongest association with the height of children; number of younger, siblings, mother's age, father's social class, and mother's smoking had rather less influence. Wingerd and Schoen (1974) in the United States of America found that $88.6 \%$ of 
the explained variation of height at the age of five years was accounted for by parental height.

It is generally accepted that the relationship between the height of children and that of their parents is largely due to common genes. In part, it may also be a result of common environmental factors, as Mueller (1976) has recently emphasised. After reviewing 24 studies of parent-child height correlation, he concluded that differences in correlations among the 24 studies could be accounted for by what geneticists call preferential marriage, and by nutritional background; it is also possible that varying degrees of inaccuracy in height measurements might explain some of the differences. In our study, the heights of children were accurately measured, but parents' heights were only reported, so our parent-child correlation (particularly between father and child) may underestimate the true value.

The heterogeneity of parent-child correlations found in the international literature (Mueller, 1976) is not seen in the British surveys. In our study, the correlation coefficient for mother-child was 0.40 and for father-child $\mathbf{0 . 3 5}$, in England; the figures for Scotland were 0.42 and 0.41 respectively. Our results show a slightly larger correlation than those found in other large surveys. Goldstein (1971) found a mother-child correlation of about 0.33 , and reported that Douglas found one of 0.35 .

There are several possible reasons for the limited association of social factors with attained height shown in our linear model analysis. Firstly, the variables chosen to represent social circumstances may not be the major social factors which influence height. Secondly, the influence of social factors on height might only be effective in certain sectors of the population, and in an analysis including children from all over Britain, the real effect is diluted. Thirdly, some social variables may influence height only if another underlying or coexisting factor is involved. Lastly, it can be argued that social factors do not exert a major influence on growth in developed countries like Britain.

\section{OTHER POSSIBLE SOCIAL VARIABLES AFFECTING GROWTH}

Information was also collected on family income and parents' education, but in both cases there were difficulties. We had a rather low response rate to the question on family income (70\% answered it) and several nurses reported on the reluctance of parents to respond to this question. In England, the correlation between height and income was slight, except for the category of 'no earnings', which was already accounted for by employment status. In the United States of America, a weak association only was found between height at five years of age and family income (Wingerd and Schoen), 1974). The less marked relationship between family income and attained height in this study and in the American one might mean that there is no real effect, and that the information is rather unreliable. Information on parents' education was not used in the analysis largely because of its correlation with social class; this meant that it had little to contribute once social class was included.

Nutrition is another variable in the social environment, but comprehensive nutritional data were not collected. A number of publications describe the effect of diet on height in wartime (Ellis, 1945; Tanner, 1962) and in developing countries (Rao and Singh, 1970; Jelliffe and Gurney, 1974; Beaton and Bengoa, 1976; Martorell et al., 1976) but there is little recent data on this relationship in developed countries. A survey in 1963 of the nutrition of children under five years of age revealed only a weak association between height and animal protein intake (Ministry of Health, 1968), but it was not clear whether social class accounted for the nutritional differences. The difficulties of collecting information on diet from large samples in a longitudinal study have not been overcome.

SOCIAL DEPRIVATION

AND ATTAINED HEIGHT

Although social variables are apparently less important than biological ones, they still have a significant effect, and this is stronger in some social strata than in others. The three social factors we have shown to be associated with height are often associated with each other. Thus, in Social Class V, where conditions are less favourable, there is a tendency to have larger families and unemployment is more common.

In England, sibship size affected the height of children only in manual social classes, although those with four or more siblings were generally worse off whatever their social class. This could mean that sibship size is associated with height through economic hardship, and that once this has disappeared differences apparently due to sibship size are partially eliminated. In the Scottish sample, no interaction was found between sibship size and social class. Fig. 3 shows that sibship size still affects height in both manual and non-manual groups. The association of family size with height has often been reported (Scott, 1961; Douglas and Simpson, 1964; Goldstein, 1971). Goldstein described an interaction between mother's parity and social class on height, showing that the height of children with three or more older siblings was affected by father's social class more than that of children with fewer 
older siblings. He ignored this interaction because in his complete fitted model the relationship was not significant. Douglas and Simpson (1964) reported that the height of children in the upper social classes was not related to sibship size, whereas in the other social classes it was strongly influenced by sibship size. However, this interaction between social class and sibship size was marked only in boys.

That social factors still influence the height of primary schoolchildren in Britain is an indication that even today some children are relatively deprived. In Sweden, it has been shown that growth and maturation in adolescents is no longer related to social class (Lindgren, 1976). Roberts et al. (1971; 1975) found that in South Shields and south-east Northumberland there was no difference in the age of menarche for girls in different social classes; but it was related to sibship size. They also reported that there was no association between physical growth and social class in adolescence, but they felt that their samples were too small, when subdivided into age groups and menarcheal status, for them to emphasise this finding.

Our results showed a relationship between father's unemployment and height of children. Although this association was not always significant within social class, the trend was consistent. In Scotland, unemployment had a larger association with the height of children than social class. Unemployment is associated with a difference in each social class group of 0.25 to $0.65 \mathrm{SDS}(1.5 \mathrm{~cm}$ to $3.5 \mathrm{~cm})$ in the preliminary analysis, and children grow between $5 \mathrm{~cm}$ and $7 \mathrm{~cm}$ a year in the age range studied. So short-term unemployment cannot account for all the difference. About $20 \%$ of the unemployed population in England in 1972 to 1975 were out of work for more than 52 weeks (Department of Employment, 1976). In families where the breadwinner is likely to be unemployed for longer periods than other men in the same type of occupation, it may be more difficult to maintain the well-being of children.

Analysis of the height of parents showed two effects. Firstly, those in the lower social classes were shorter; secondly, the unemployed in those classes were shortest. The existence of the same tendency in two generations reflects a complex situation. Some research workers consider that environment and opportunities in life may affect height. Others feel that height or other associated factors enable an individual to occupy a particular social environment. The social class trend of height in children and adults is compatible with an environmental effect, but the differences in height between employed and unemployed fathers in the manual classes perhaps indicate that genetic factors confer an advantage on taller individuals. This may be because of height alone, or because of other associated factors, but such speculation is outside the scope of this paper. Schreider (1964) showed that women can migrate from an upper to a lower social class, or vice versa, by marriage in relation to their height; upward social mobility by marriage was found to be greater for taller girls in lower social classes. Tanner (1966) analysed the relationship between height, intelligence, and social circumstances in this context.

It appears that a mixture of genetic endowment and social environment is responsible for the results. Further analysis of longitudinal data and the most recent cross-sectional data obtained should permit an assessment of the extent to which these results illustrate a persistent feature of the influence of social and biological factors on the height of children in England and Scotland. It may also be possible to assess, by examining several cohorts of primary schoolchildren from this study, whether variation in height is affected by changes in social circumstances in the United Kingdom.

We thank Professor W. W. Holland, Dr. C. Florey, and our fieldworkers and other helpers. This study was supported by the Department of Health and Social Security.

Reprints from R. J. Rona, Department of Community Medicine, St. Thomas's Hospital Medical School, London SE1 7EH.

\section{References}

Beaton, G. H., and Bengoa, J. M. (1976). Practical population indicators of health and nutrition. Annex 3. In Nutrition in preventive medicine. Edited by G. $\mathrm{H}$. Beaton and J. M. Bengoa. Monograph Series No. 62. WHO: Geneva.

Department of Employment (1976). British Labour Statistics Year Book 1976. HMSO: London.

Department of Health and Social Security (1973). Reports on health and social subjects, No. 6. First Report by the Subcommittee on Nutritional Surveillance. HMSO: London.

Douglas, J. W. B., and Simpson, H. R. (1964). Height in relation to puberty, family size, and social class: A longitudinal study. Milbank Memorial Fund Quarterly, 42, (I), 20-35.

Ellis, R. W. B. (1945). Growth and health of Belgian children during and after the German occupation (1940-1944). Archives of Disease in Childhood, 20, 97-109.

Goldstein, H. (1971). Factors influencing the height of seven-year-old children: results from the National Child Development Study. Human Biology, 43, 92-111.

Irwig, L. M. (1976). Surveillance in developed countries with particular reference to child growth. International Journal of Epidemiology, 5, 57-61. 
Jelliffe, E. F. P., and Gurney, M. (1974). Definition of the problem. In Nutrition and Malnutrition, Identification and Measurement. Edited by A. F. Roche and F. Faulkner. Advances in Experimental Medicine and Biology, 49, 1-13.

Lindgren, G. (1976). Height, weight, and menarche of Swedish urban schoolchildren with relative socioeconomic and regional factors. Annals of Human Biology, 3, 501-528.

Martorell, R., Lechtig, A., Yarbrough, Ch., Delgado, H., and Klein, R. E. (1976). Protein-calorie supplementation and post-natal physical growth: $\mathbf{A}$ review of findings from developing countries. Archivos Latino Americanos de Nutricion, 26, 115-127.

Ministry of Health (1968). A pilot survey of the nutrition of young children in 1963. HMSO: London.

Mueller, W. H. (1976). Parent-child correlations for stature and weight among school-aged children: A review of 24 studies. Human Biology, 48, 379-397.

Nelder, J. A. (1975). General Linear Interactive Modelling; GLIM Manual. Release 2. Distributed by the Numerical Algorithms Group. Copyright Royal Statistical Society: London.

Rao, K. V., and Singh, D. (1970). An evaluation of the relationship between nutritional status and anthropometric measurements. American Journal of Clinical Nutrition, 23, 89-93.

Registrar General (1970). Classification of Occupations. HMSO: London.
Roberts, D. F., Danskin, M. H., and Chinn, S. (1975). Menarcheal age in Northumberland. Acta Paediatrica Scandinavica, 64, 845-852.

Roberts, D. F., Rozner, L. M., and Swan, A. V. (1971). Age at menarche, physique, and environment in industrial north-east England. Acta Paediatrica Scandinavica, 60, 158-164.

Rona, R. J., and Altman, D. E. (1977). Standards of attained height, weight and triceps skinfold. Annals of Human Biology, 4, 501-523.

Schreider, E. (1964). Recherches sur le stratification sociale des caractères biologiques. Byotypologie, 26, 105-135.

Scott, J. A. (1961). Report on the heights and weights (and other measurements) of school pupils in the county of London in 1959. London County Council.

Tanner, J. M. (1962). Growth at adolescence. Blackwell: London.

Tanner, J. M. (1966). Galtonian eugenics and the study of growth: The relation of body size, intelligence test score, and social circumstances in children and adults. Eugenics Review, 58, 122-135.

Tanner, J. M., Whitehouse, R. H., and Takaishi, M. (1966). Standards from birth to maturity for height, weight, height velocity and weight velocity: British children. Archives of Disease in Childhood, 41, 613-635.

Wingerd, J., and Schoen, E. J. (1974). Factors influencing length at birth and height at five years. Pediatrics, 53, 737-741. 